\title{
A new squat lobster (Decapoda: Anomura: Galatheidae) from an active thermal vent area in the North Fiji Basin, SW Pacific
}

Keiji Baba

\begin{abstract}
Munidopsis sonne new species herein described from the North Fiji Basin is the seventh species of Munidopsis associated with active thermal vents. It is related to $M$. hastifer Benedict, 1902, and M. serratifrons $A$. Milne Edwards, 1880 , in the serrate rostral lateral margins and tuberculate carapace but differentiated from these species by the presence of epipods on pereopods 1-3 and lack of distinct spines on the carapace and abdomen.
\end{abstract}

Collections made by recent explorations of active thermal vent areas in the southwest Pacific included five species of Galatheidea (two of Uroptychus, one of Munida and two of Munidopsis) (Baba \& Türkay, 1992; Baba \& de Saint Laurent, 1992). Additional material from the North Fiji Basin recently made available by Michael Türkay at Frankfurt includes another new species of Munidopsis, which is hereby described and illustrated. It represents the seventh species of Munidopsis associated with active hydrothermal vents, the other four species having been described from the eastern Pacific and Mariana Back Arc Basin (Williams \& Van Dover, 1983; Van Dover et al., 1985; Williams, 1988; Williams \& Baba, 1990).

Measurements indicated under "Material" show the postorbital carapace length. The type material will be deposited in the Senckenberg Museum at Frankfurt, a.M. (SMF).

\section{Munidopsis sonne new species}

Figs. 1, 2

Type material. - Holotype, ovig. ㅇ (10.5 mm), SMF 23041; paratype, 1 o (10.8 mm), SMF 23042; SO-99, $16^{\circ} 59.49^{\prime} \mathrm{S}, 173^{\circ} 54.83^{\prime} \mathrm{E}, 1992 \mathrm{~m}, 24$ Jan. 1995, sample 98 GTV (TV grab).

Description. - Carapace, excluding rostrum, longer than wide, moderately convex from side to side, cervical groove not sharply defined; dorsal surface covered with numerous tubercle-like setiferous processes; anterior gastric region with pair of broad, antero-posteriorly compressed, truncate processes, posterior gastric region defined as backwardly pointed triangle by shallow groove. Cardiac region divided into anterior and posterior portions by deep transverse depression without tubercles. Rostrum nearly triangular (in holotype) or somewhat constricted near base (in paratype), nearly horizontal, length slightly more than $1 / 3$ of remaining carapace; dorsal surface ridged in midline; lateral margins somewhat convex (more distinctly so in paratype), with row of small spines. Lateral limit of orbit distant from eye, ventral orbital margin with anteriorly directed tuberculate process near lateral extremity; front margin lateral to orbit concavely oblique. Lateral margins of carapace convexly convergent posteriorly, with weak constriction at end of cervical groove and between anterior and posterior branchial regions; anterior branchial 

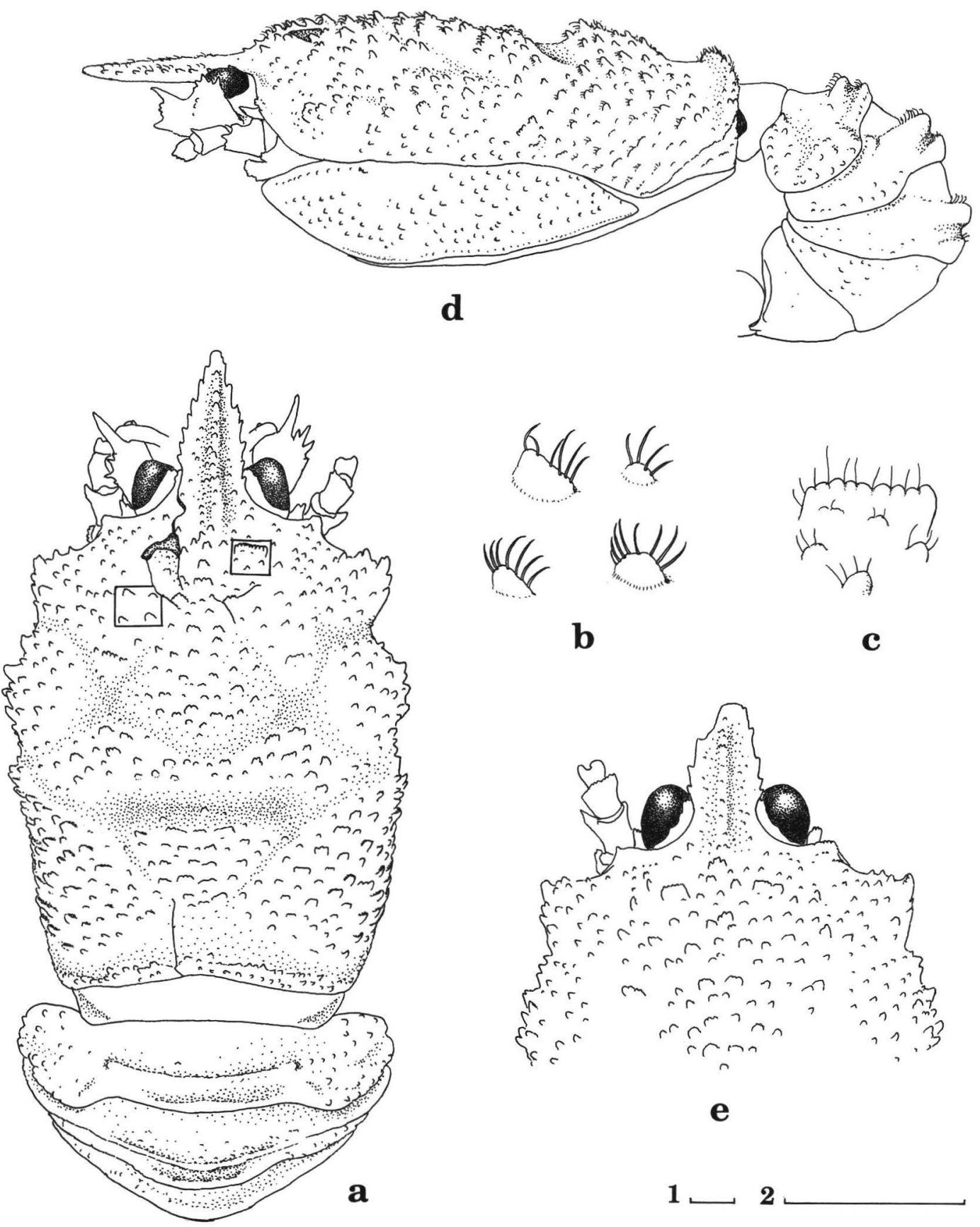

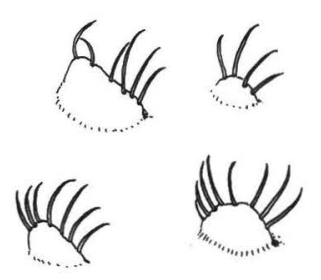

b

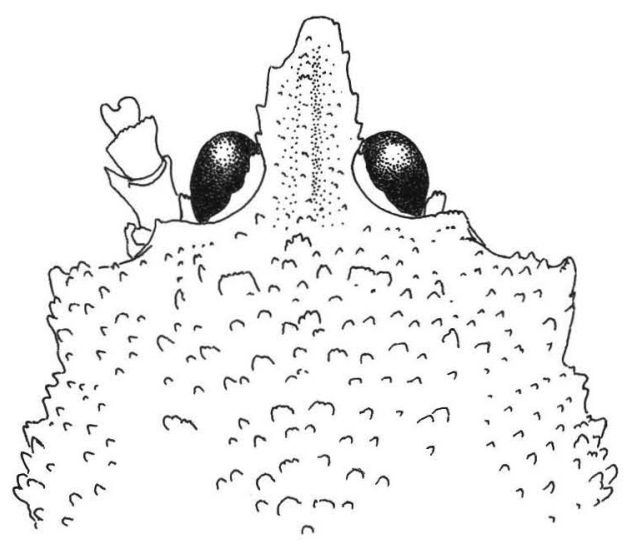

$\mathbf{e}$

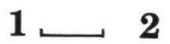

Fig. 1. Munidopsis sonne new species; a-d, female holotype; e, male paratype: a, carapace and abdomen, dorsal view; $b$, tubercles in left square on Fig. $a$, enlarged; $c$, tubercles in right square on Fig. a, enlarged; d, carapace and abdomen (posterior portion omitted), lateral view; e, carapace, anterior half, dorsal view. Scales $=1 \mathrm{~mm}$; scale 1 for a, d, e; scale 2 for b, c. 
region laterally inflated. Posterior margin of carapace somewhat concave, preceded by raised tuberculate ridge. Pterygostomian flap anteriorly ending in rounded margin, surface covered with tubercles much smaller than those on carapace.

Sternal plastron narrow relative to length; anterior portion as illustrated; third thoracic sternite $1 / 3$ as wide as fourth thoracic sternite, anterior margin with apposed dentate processes, anterolateral angle produced; fourth thoracic sternite subtriangular.

Abdomen unarmed; 2 transverse ridges without spines on second to fourth tergites, scattered tubercles on second and third pleura; fifth and sixth tergite without ridges. Sixth tergite with weak posterolateral lobe, posterior margin not produced. Telson relatively long, lengthwidth ratio 0.93 in ovigerous female holotype, 0.98 in male paratype; divided into 8 platelets, central platelet absent in holotype; in male, midlateral platelet with row of stiff setae on lateral margin.

Eyes immovable, relatively wide, corneal region narrowed distally.

Antennular basal segment cristate dorsolaterally, with row of several spines, distolateral (dorsal) margin with prominent spine, distomesial margin unarmed. Antennal peduncles long relative to width, basal (first) segment with 2 rugae ventro-distomesially; second segment with short distal spine on mesial and lateral margins, distomesial one blunt, third segment unarmed.

Third maxillipeds with sparse short setae. Basis with 4-6 obsolescent teeth on mesial ridge. Ischium with row of numerous denticles on mesial ridge. Merus widened medially, narrowed distally, width of distal end less than half that measured at midlength; flexor margin with 4-5 spines of irregular sizes on distal half, extensor margin with 1-4 small spines.

Chelipeds proximally subcylindrical, distally somewhat depressed, covered with tubercular processes and blunt short spines, both setiferous (ventrally less tubercular), length 2.0 (female) or more than 2.5 (male) times postorbital carapace length. Merus with prominent distomesial spine. Carpus also with strong distomesial spine smaller than that of palm. Palm slightly more than twice as long as wide, slightly longer than movable finger. Fingers relatively wide, ventrally spoon-shaped when closed, distally not crossing but fitting to each other with intermeshing teeth when closed.

Walking legs successively diminishing in length posteriorly, meri in particular; subcylindrical, covered with tubercular processes on meri, carpi and propodi. Propodi about twice as long as dactyli, flexor margin with spine-like distal seta. Dactyli rather straight and distally curving on first and second walking legs, more distinctly curving on third; ending in sharp curved spine preceded by inclined setae along distal two-thirds of flexor margin. First walking leg not reaching end of palm.

Epipods present on chelipeds, first and second walking legs.

Female holotype bearing 4 ova, each measuring $2.3 \times 2.5 \mathrm{~mm}$ in diameter.

Etymology. - Named for the German research vessel "Sonne" used to collected the material.

Remarks. - The new species resembles $M$. hastifer Benedict, 1902, only known by the type material from Japan in the tuberculate carapace and appendages and the laterally serrate rostrum. Because of the brevity of the original description the type material of $M$. hastifer (3 males, syntypes, USNM 26164, off Honshu, Japan, 120-265 fm) was examined.

The following characters displayed by the types of $M$. hastifer clearly discriminate between the two species: the carapace has a spinose appearance while it is tubercular in $M$. sonne; the abdominal tergites and pleura bear strong spines at 

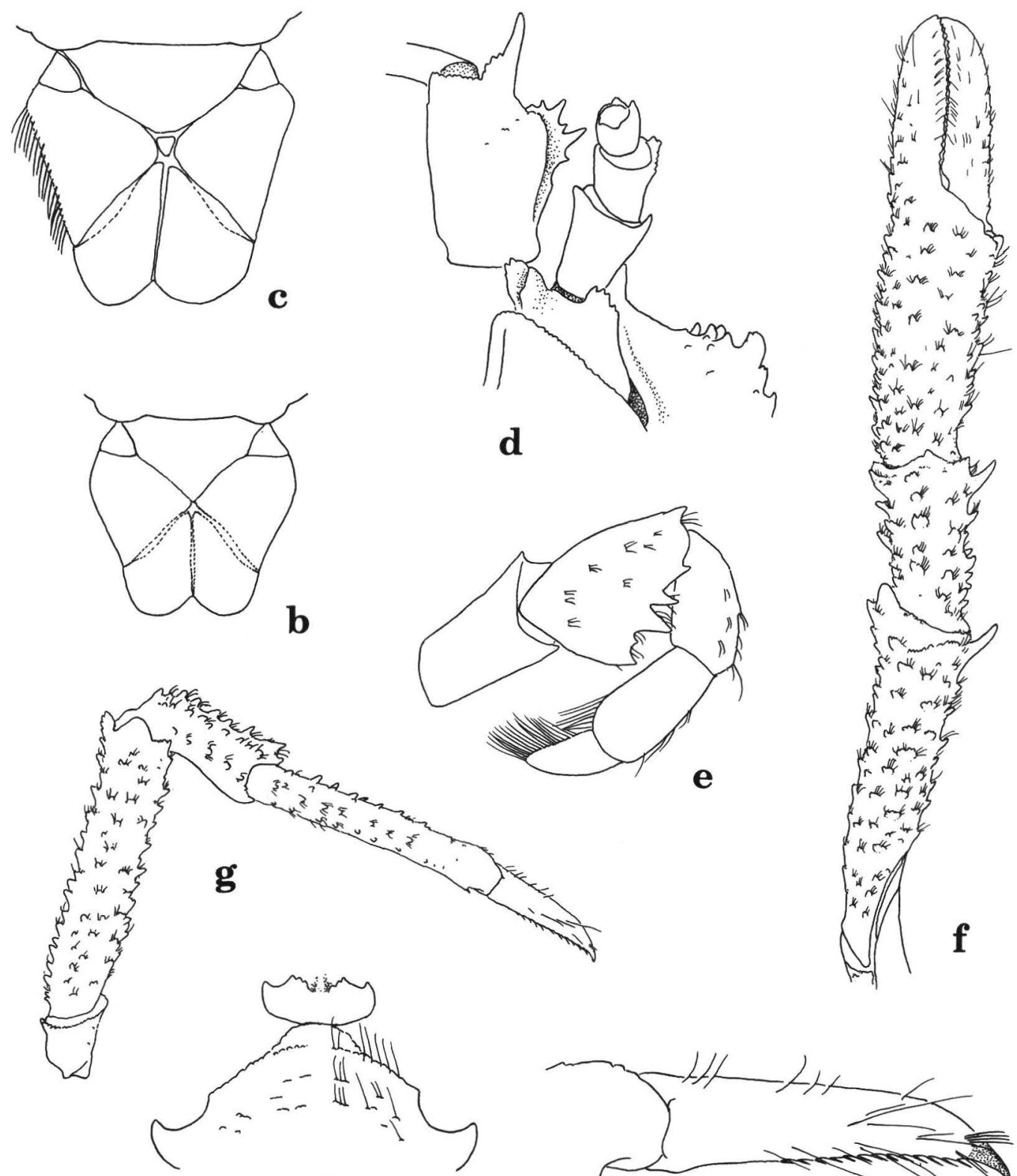

$\mathbf{a}$

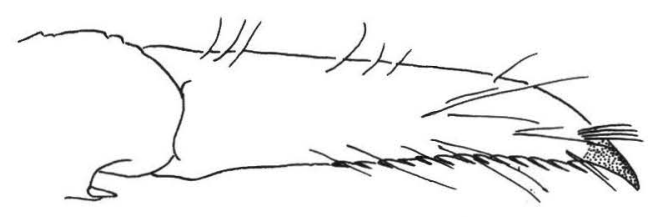

h

1

2

3

4.

Fig. 2. Munidopsis sonne new species: $\mathrm{a}, \mathrm{b}, \mathrm{d}-\mathrm{h}$, female holotype; $\mathrm{c}$, male paratype: a, anterior part of thoracic sternum; $b$, telson; $c$, same (marginal setae on right midlateral platelet omitted); $\mathrm{d}$, anterior part of cephalothorax showing antenna and antennal peduncle, ventral view; e, endopod of right third maxilliped, lateral view; $f$, left cheliped, dorsal view; $g$, first walking leg, lateral view; $h$, distal part of same. Scales $=1 \mathrm{~mm}$; scale 1 for $b, f$, g; scale 2 for c; scale 3 for a, d, $\mathrm{e}$; scale 4 for h. 
least on the second and third segments whereas on $M$. sonne spines are absent; the telson is wide relative to length (length-width ratio, 0.71 versus $0.93-$ $0.98)$; the eyes are slightly movable in dorsoventral direction, bearing a papilla-like dorsal spine proximal to the cornea but in $M$. sonne the eyes are immovable, without any eyespine; the produced lateral angle of the orbit is nearly contiguous to the eye whereas in $M$. sonne it is not produced and rather distant from the eye; the antennal peduncles are relatively wide, bearing a strong distolateral spine on the first and second segments, instead of being elongate, without prominent spines in $M$. sonne; the dactyli of the walking legs bear a row of small spines along the twothirds of the extensor margin while spines are absent on the extensor margin in $M$. sonne; epipods are absent from all pereopods, but present on P1-P3 in M. sonne.

The shape of the rostrum also links the new species to $M$. serratifrons A. Milne Edwards, 1880 from the western Atlantic. However, the latter species is characterized by the less tuberculate and rather granular carapace, bearing distinct spines on the epigastric, cardiac, lateral branchial regions, and along the posterior margin of the carapace; the abdomen bearing spines on the second to fourth tergites; the eyes bearing a papilla-like process as in $M$. hastifer; the first segment of the antennal peduncle bearing a prominent distolateral spine, and all pereopods lacking epipods. These characters are apparent mostly in the description and illustrations provided by Milne Edwards \& Bouvier (1897) and confirmed by examination of specimens of that species now in the collection of the Smithsonian Institution (1 ovigerous female, Albatross St. 2154 off Havana, Cuba, 310 fm, USNM 7796, recorded by Benedict (1902:326); 1 male taken at Albatross St. 2351 off Cuba, 426 fm, USNM 21306).

\section{Acknowledgments}

I thank Michael Türkay and Holger Hosemann of the Senckenberg Museum, Frankfurt, for making the interesting material available for study. The comparative material was examined during my visit to the Smithsonian Institution in 1989. I thank Raymond B. Manning for laboratory facilities and hospitality. The manuscript benefited from reviews by Peter J. F. Davie of the Queensland Museum, and Colin L. McLay of the University of Canterbury.

\section{Literature Cited}

Baba, K., \& de Saint Laurent, M., 1992. Chirostylid and galatheid crustaceans (Decapoda: Anomura) from active thermal vent areas in the southwest Pacific. Scientia marina, 56(4): 321-332.

Baba, K., \& Türkay, M., 1992. Munida magniantennulata, a new deepsea decapod crustacean from active thermal vent areas of Valu-Fa-Ridge in the Lau Basin, SW-Pacific (Anomura: Galatheidae). Senckenbergiana maritima, 22: 203-210.

Benedict, J. E., 1902. Descriptions of a new genus and forty-six new species of crustaceans of the family Galatheidae, with a list of the known marine species. Proceedings of the United States National Museum, 26: 243-334.

Milne Edwards, A., 1880. Reports on the results of dredging under the supervision of Alexander Agassiz, in the Gulf of Mexico and in the Caribbean Sea, etc. VIII. Etudes preliminaires sur les Crustacés. Bulletin of the Museum of Comparative Zoology at Harvard College, in Cambridge, 8(1): 1-68, pls $1,2$.

- \& Bouvier, E. L., 1897. Reports on the results of dredging, under the supervision of Alexander Agassiz, in the Gulf of Mexico (1877-78), in the Caribbean Sea (1878-79) and along the Atlantic coast of the United States (1880), etc. XXXV. Description des Crustacés de la famille des Galathéidés recueillis pendant l'Expédition. Mémoirs of the Museum of Comparative Zoology at Harvard College, 19(2): 1-141, pls. 1-12.

Van Dover, C. L., Factor, J. R., Williams, A. B. \& Berg, C. J., Jr., 1985. Reproductive patterns of decapod crustaceans from hydrothermal vents. Bulletin of the Biological 
Society of Washington, No. 6: 223-227.

Williams, A. B., 1988. New marine decapod crustaceans from waters influenced by hydrothermal discharge, brine, and hydrocarbon seepage. Fishery Bulletin, 86(2): 263287.

, \& Baba, K., 1990. New squat lobsters (Galatheidae) from the Pacific Ocean: Mariana Back Arc Basin, East Pacific Rise, and Cascadia Basin. Fishery Bulletin,
87(4): 899-910.

$\longrightarrow$, \& van Dover, C. L., 1983. A new species of Munidopsis from submarine thermal vents of the East Pacific Rise at $21^{\circ} \mathrm{N}$ (Anomura: Galatheidae). Proceedings of the Biological Society of Washington, 96(3): $481-488$.

Kumamoto University Faculty of Education, 2-40-1 Kurokami, Kumamoto 860, Japan. 